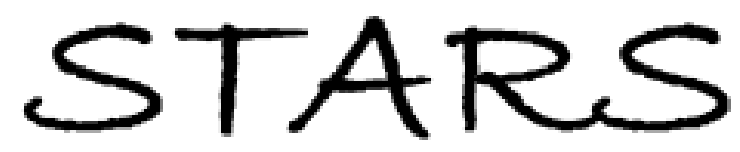

University of Central Florida

STARS

Faculty Bibliography 2000s

Faculty Bibliography

$1-1-2000$

\title{
Photostability enhancement of an azobenzene photonic polymer
}

\author{
A. Galvan-Gonzalez \\ University of Central Florida \\ K. D. Belfield \\ University of Central Florida \\ G. I. Stegeman \\ University of Central Florida \\ M. Canva \\ K. -P. Chan
}

See next page for additional authors

Find similar works at: https://stars.library.ucf.edu/facultybib2000

University of Central Florida Libraries http://library.ucf.edu

This Article is brought to you for free and open access by the Faculty Bibliography at STARS. It has been accepted for inclusion in Faculty Bibliography 2000s by an authorized administrator of STARS. For more information, please contactSTARS@ucf.edu.

\section{Recommended Citation}

Galvan-Gonzalez, A.; Belfield, K. D.; Stegeman, G. I.; Canva, M.; Chan, K. -P.; Park, K.; Sukhomlinova, L.; and Twieg, R. J., "Photostability enhancement of an azobenzene photonic polymer" (2000). Faculty Bibliography 2000s. 7855.

https://stars.library.ucf.edu/facultybib2000/7855

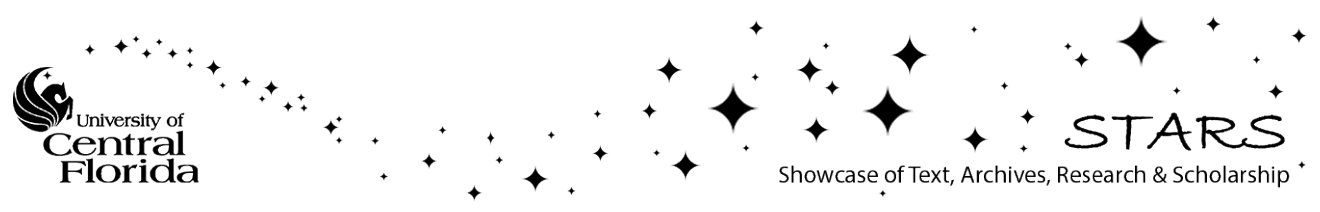


Authors

A. Galvan-Gonzalez, K. D. Belfield, G. I. Stegeman, M. Canva, K. -P. Chan, K. Park, L. Sukhomlinova, and R. J. Twieg 


\section{Photostability enhancement of an azobenzene photonic polymer}

Cite as: Appl. Phys. Lett. 77, 2083 (2000); https://doi.org/10.1063/1.1313809

Submitted: 23 May 2000 . Accepted: 03 August 2000 . Published Online: 26 September 2000

A. Galvan-Gonzalez, K. D. Belfield, G. I. Stegeman, M. Canva, K.-P. Chan, K. Park, L. Sukhomlinova, and R. J. Twieg

\section{ARTICLES YOU MAY BE INTERESTED IN}

Wavelength dependence of 4-dimethylamino-4-nitrostilbene polymer thin film photodegradation

Applied Physics Letters 73, 912 (1998); https://doi.org/10.1063/1.122035

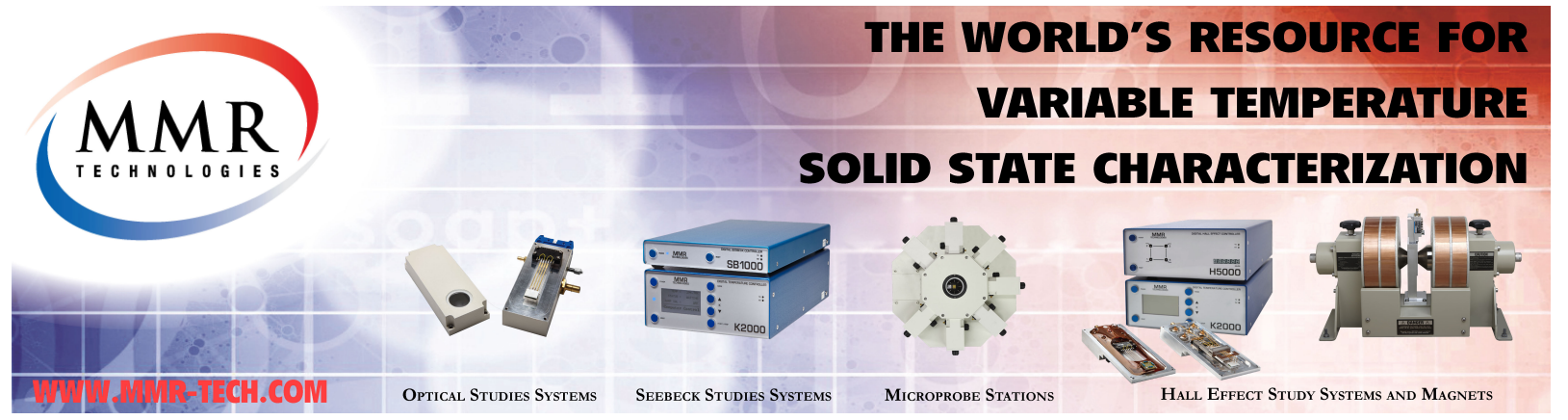




\title{
Photostability enhancement of an azobenzene photonic polymer
}

\author{
A. Galvan-Gonzalez, K. D. Belfield, and G. I. Stegeman \\ School of Optics/Center for Research and Education in Optics and Lasers (CREOL), \\ University of Central Florida, P.O. Box 162 700, 4000 Central Florida Blvd., Orlando, Florida 32816-2700 \\ M. Canva \\ Laboratoire Charles Fabry de l'Institut d'Optique, IOTA Institut d'Optique Théorique et Appliquée, \\ Centre National de la Recherche Scientifique, CNRS UMR 8501, Université d'Orsay-Paris XI, BP 147, \\ 91403 Orsay Cedex, France \\ K.-P. Chan \\ Molecular OptoElectronics Corporation (MOEC), 877 25th Street, Watervliet, New York 12189-1903 \\ K. Park, L. Sukhomlinova, and R. J. Twieg ${ }^{\text {a) }}$ \\ Department of Chemistry, Kent State University, Kent, Ohio 44242-0001
}

(Received 23 May 2000; accepted for publication 3 August 2000)

\begin{abstract}
We have found that the presence of a methacrylate group on an azobenzene electro-optic chromophore can provide an enhancement in photostability of up to one or two orders of magnitude. Systematic studies involving the change in chromophore structure and atmospheric environment indicate that the photostabilization is due to antioxidant action by the unsaturated functional group. (C) 2000 American Institute of Physics. [S0003-6951(00)00540-4]
\end{abstract}

It has been demonstrated that electro-optic polymers possess some superior properties for application in photonics devices relative to inorganic materials. For example, some donor-acceptor chromophores possess very large molecular nonlinearities and poled polymer modulators containing them can operate at low drive voltages and large bandwidths even in excess of $100 \mathrm{GHz}{ }^{1,2}$ Two of the most interesting applications for electro-optic polymers are in communications and radar where the devices must operate for periods of years without need for replacement. ${ }^{1,3}$ However, organic materials currently available may fall short in such applications as has been demonstrated in recent evaluations wherein the projected device lifetimes were limited by photodegradation to just a few months at best. ${ }^{4-7}$ The two most common degradation mechanisms appear to involve trans-cis isomerization and photo-oxidation. Depending on the general chromophore structure the isomerization can be highly reversible (azobenzene), partly reversible (stilbene), or nonoperative (biphenyl). Likewise, the propensity for photo-oxidation, which will always be irreversible, is also highly structure dependent and perhaps dominant in many chromophore families. ${ }^{4-6}$ Here we report the observation of a surprising photostability enhancement due to the presence of a methacrylate group in an azobenzene chromophore. This functional group appears to preferentially interact with some reactive oxygen species thereby reducing photo-oxidation of the azobenzene structure and increasing net photostability.

The structures and designations of the seven azobenzene chromophores studied here are found in Table I. These azodyes may be considered as modifications of the classical electro-optic chromophore Disperse Red 1 (DR1) which has a nitro acceptor group and a donor nitrogen atom substituted with an ethyl group and a hydroxyethyl group. In all cases here the nitro acceptor is constant and the most important

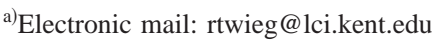

structure modifications take place in the donor group. Esterification of the hydroxyethyl group of DR1 with methacrylic acid gives the unsaturated methacrylate ester dye DR1-M while esterification with methylpropanoic acid and acetic acid gives the saturated ester derivatives DR1-MP and DR1-A, respectively. The dye with two $n$-butyl groups on the donor nitrogen, BU2AZ, is included for comparison to the DR1 type compounds. Two additional dyes in which the donor nitrogen atom is replaced by a weaker oxygen donor atom, a 2-ethylhexyloxy ether in the case of EHDNPB and an ether derived from lactic acid in the case of ILDNPB, are also included in this study. Ether donor azobenzenes like these had been studied earlier as photorefractive chromophores. ${ }^{8,9}$

The first oxidation potential of each of these compounds and the wavelength of the maximum of the charge transfer absorption are provided for each compound in Table I. The oxidation potentials of such azodyes have been demonstrated to correlate with their thermal stability and, very generally, the compounds with the better donors have lower oxidation potentials, lower thermal stability, and longer wavelength absorption. ${ }^{10,11}$ Oxidation potentials were measured at a $\mathrm{Pt}$ electrode in a three electrode cell in millimolar concentration in acetonitrile containing $0.1 \mathrm{M}$ tetraethylammonium tetrafluoroborate at sweep speed of $300 \mathrm{mV} / \mathrm{s}$ and $E_{\text {ox }}$ is the maximum of the first oxidation wave. Based on the chromophores examined here to date, there appears to be no reliable correlation between oxidation potential and photochemical stability reflecting the inherent complexity of the photochemistry of these molecules relative to their thermal chemistry.

The photostability of DR1 in both side-chain and guesthost formats has been studied before and two reaction pathways originating from the dominant excited charge transfer state, namely trans-cis isomerization and photo-oxidation, were identified. ${ }^{4}$ The key to interpreting degradation mecha- 
TABLE I. The structures, symbols, and names for the azobenzene chromophores studied along with their respective oxidation potentials $E_{\mathrm{ox}}(\mathrm{V})$, $\lambda_{m}$ (nm in PGMEA solution), and the $B$ value.

\begin{tabular}{|c|c|c|}
\hline $\begin{array}{c}\text { Symbol } \\
\text { Name }\end{array}$ & Chromophore Structure & $\begin{array}{c}E_{o x} \\
\lambda_{\mathrm{m}} \\
B\end{array}$ \\
\hline $\begin{array}{c}\bullet \\
\text { DR1 }\end{array}$ & & $\begin{array}{c}1.064 \\
466 \\
1 \times 10^{7} \\
\end{array}$ \\
\hline $\begin{array}{c}\Delta \\
\text { DR1-M }\end{array}$ & & $\begin{array}{c}1.144 \\
470 \\
3 \times 10^{8}\end{array}$ \\
\hline $\begin{array}{c}\nabla \\
\text { DR1-MP }\end{array}$ & & $\begin{array}{c}1.094 \\
475 \\
1 \times 10^{7}\end{array}$ \\
\hline $\begin{array}{c}\diamond \\
\text { DR1-A }\end{array}$ & & $\begin{array}{c}1.094 \\
475 \\
9 \times 10^{6} \\
\end{array}$ \\
\hline $\begin{array}{c}\square \\
\mathrm{BU} 2 \mathrm{AZ}\end{array}$ & & $\begin{array}{c}1.034 \\
490 \\
1 \times 10^{7}\end{array}$ \\
\hline $\begin{array}{c}+ \\
\text { EHDNPB }\end{array}$ & & $\begin{array}{c}1.66 \\
405 \\
1 \times 10^{7}\end{array}$ \\
\hline $\begin{array}{c}X \\
\text { ILDNPB }\end{array}$ & & $\begin{array}{c}1.69 \\
395 \\
6 \times 10^{6}\end{array}$ \\
\hline
\end{tabular}

nisms involves the analysis of changes in the ultravioletvisible absorption spectrum as a function of irradiation time in different environments. Typical data is provided in Fig. 1 for DR1 in polymethylmethacrylate (PMMA). Here photodegradation in the oxygen atmosphere is faster than in the nitrogen atmosphere and the resulting spectra after $2 \mathrm{~h}$ of irradiation are very different indicative of different degradation pathways and different product mixtures. Based on such data, it was concluded that the chemical changes in nitrogen are primarily due to trans-cis isomerization while in oxygen photo-oxidation is a dominant mechanism. In any case, since the trans-cis isomerization is highly reversible, inevitably some oxidation mechanisms contribute to the irreversible depletion of DR1.

Using the same experimental approach (described in detail elsewhere), ${ }^{5}$ the extent of photodegradation of the other chromophores in Table I loaded at $4 \%$ by weight in PMMA was determined at different times while exposed to nitrogen, air or oxygen. In Fig. 2 the result for DR1-M is shown. The spectra for all three of the atmospheres for DR1-M are essentially the same (in contrast to the previous DR1 case) and they resemble the spectra obtained in a nitrogen atmosphere for DR1 because the features attributed to oxidative products (the broad peak with $\lambda_{\max }$ near $380 \mathrm{~nm}$ ) are absent. In contrast to the factor of three difference in photodegradation rates found for DR1 in oxygen and nitrogen atmosphere the photodegradation rates found for DR1-M are much more

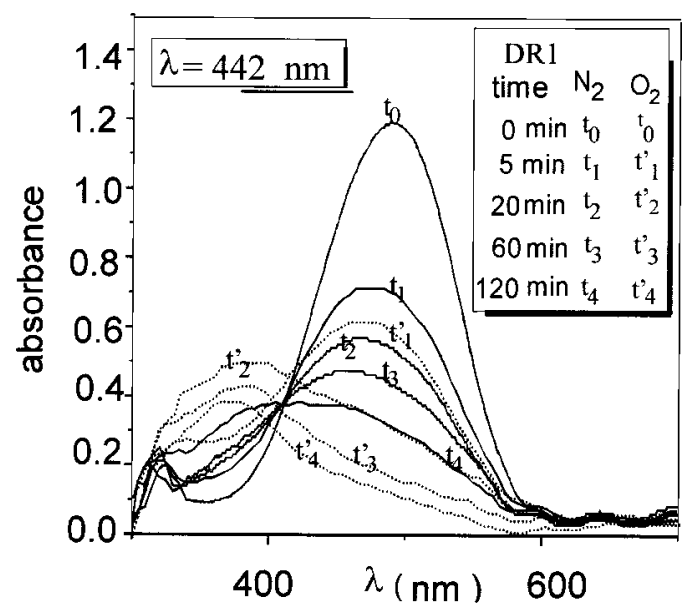

FIG. 1. The evolution of the absorption spectrum of a 3.12- $\mu$ m-thick film of guest DR1 in host PMMA when irradiated with $442 \mathrm{~nm}$ radiation for different periods of time in nitrogen (solid line) and oxygen (dotted line) atmospheres.

similar. To an approximation the photodegradation of DR1-M is independent of the atmosphere, implying that trans-cis isomerization is the dominant mechanism and the contribution of photo-oxidation has been reduced. Under equivalent illumination conditions the rate of change found in the DR1-M spectra is much slower than for DR1, indicating the former is overall more photostable. The $B$ value for DR1-M is some 30 times larger than for the other six chromophores that all have similar B values.

The atmosphere-dependent degradation behavior displayed by DR1 in Fig. 1 is observed for all the other chromophores in Table I except for DRI-M. For example, although DR1-MP differs from DR1-M only in the degree of unsaturation of the ester, it has a degradation rate intermediate between that of DR1 and DR1-M and has an atmosphere sensitivity resembling that of DR1. The unsaturated methacrylate group in DR1-M is not a conventional antioxidant structure although the interactions of oxygen with acrylates and other alkenes are long appreciated and highly complicated. $^{12-14}$

Our previous work has shown that, at a given pump wavelength, the key photodegradation figure of merit, $B / \sigma$,

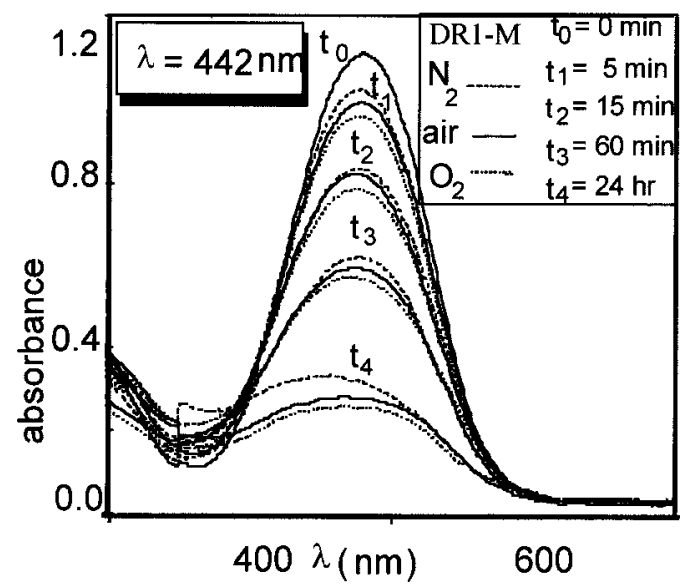

FIG. 2. The evolution of the absorption spectrum of a 3.25- $\mu \mathrm{m}$-thick film of guest DR1-M in host PMMA when illuminated with $442 \mathrm{~nm}$ radiation for different periods of time in nitrogen (dashed line), air (solid line), and oxygen (dotted line) atmospheres. 


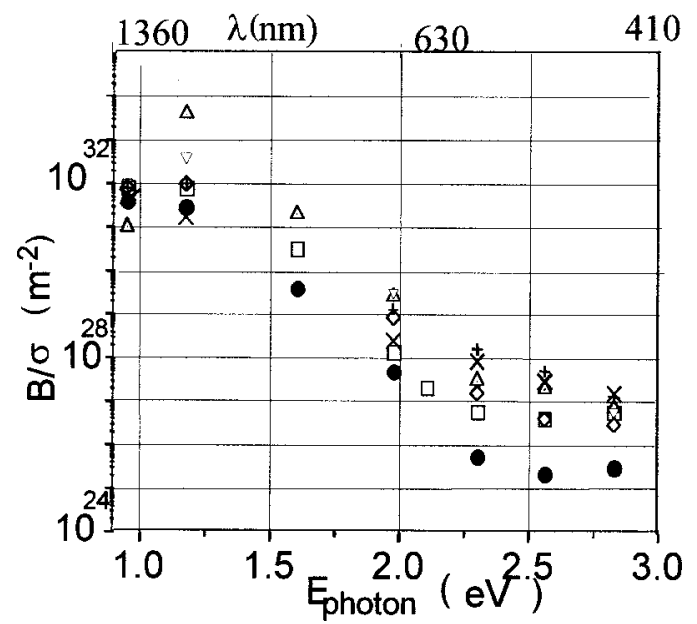

FIG. 3. The wavelength dispersion of the photodegradation figure of merit $B / \sigma$ for all the chromophores listed in Table I. The identifying symbols are given in Table I.

is measured directly by monitoring the change in sample transmission in the long wavelength tail of the absorption peak associated with the dominant charge transfer state. Here $B$ is the average number of absorption related events, $B^{-1}$ is the quantum efficiency for the molecule to change its structure on return to a ground state, and $\sigma$ is the absorptivity of an individual molecule at the pump wavelength. The $1 / e$ device lifetime is then given by $\tau=B / \sigma n$ where $n$ is the photon flux. Therefore, projected device lifetimes can be compared by comparing the values of $B / \sigma$ at the wavelength of interest. Measurements of $B / \sigma$ versus wavelength are shown in Fig. 3 for the all the chromophores in Table I. As noted before, this characteristic wavelength dependence is generic to all of the electro-optic chromophores studied to date and reflects primarily the dispersion of the chromophore absorption. Clearly the photostability of DR1-M is superior to all of the other chromophores in the important communications wavelengths between 1 and $2 \mu \mathrm{m}$ and at $1.064 \mu \mathrm{m}$ its figure of merit is two orders of magnitude better than either DR1 or BU2AZ. At shorter wavelengths the ether substituted chromophores EHDNPB and ILDNPB have lower photoreactivity than DR1-M and the other amine substituted azodyes, primarily due to their enhanced transparency and corresponding higher oxidation potentials. The relatively low value of stability at $1.32 \mu \mathrm{m}$ for all the chromophores (and especially DR1-M) has been attributed to singlet oxygen generated from a nearby absorption peak at $1.28 \mu \mathrm{m}$.

The salient question that remains is whether or not lifetimes of polymer waveguide devices might be increased by the use of such antioxidants. Device lifetimes can be predicted for the DR1 and DR1-M chromophores for typical device operating conditions wherein the polymer is formed into a channel waveguide of approximate $10 \mu \mathrm{m}^{2}$ cross section and $1 \mathrm{~mW}$ of power is continuously present. Whereas the DR1 waveguide lifetime is predicted only to be a few days the DR1-M waveguide is predicted to survive on the order of a year. In summary, we have shown that the presence of an unsaturated ester can improve the photostability of electro-optic chromophores in important wavelength regimes, probably operating by scavenging reactive oxygen species or free radicals. Further studies of this stabilization phenomenon are warranted.

At CREOL this research was supported by NSF under a GOALI program, at CREOL and IOTA by a CNRS/NSF French/US bilateral grant, at KSU by NSF ALCOM (DMR89-29147), and NIST-ATP.

${ }^{1}$ L. R. Dalton, W. H. Steier, B. H. Robinson, C. Zhang, A. Ren, S. Garner, A. T. Chen, T. Londergan, L. Irwin, B. Carlson, L. Fifield, G. Phelan, C. Kincaid, J. Amend, and A. Jen, J. Mater. Chem. 9, 1905 (1999).

${ }^{2}$ Y. Q. Shi, C. Zhang, H. Zhang, J. H. Bechtel, L. R. Dalton, B. H. Robinson, and W. H. Steier, Science 288, 119 (2000).

${ }^{3}$ S. A. Hamilton, D. R. Yankelevich, A. Knoesen, R. T. Weverka, and R. A. Hill, IEEE Trans. Microwave Theory Tech. 47, 1184 (1999).

${ }^{4}$ A. Galvan-Gonzalez, M. Canva, G. I. Stegeman, R. Twieg, A. C. Kowalczyk, and H. S. Lackritz, Opt. Lett. 24, 1741 (1999).

${ }^{5}$ A. Galvan-Gonzalez, M. Canva, G. I. Stegeman, L. Sukhomlinova, R. J. Twieg, and K.-P. Chan, J. Opt. Soc. Am. B (to be published).

${ }^{6}$ A. Galvan-Gonzalez, M. Canva, and G. I. Stegeman, Appl. Phys. Lett. 75, 3306 (1999).

${ }^{7}$ A. Galvan-Gonzalez, M. Canva, G. I. Stegeman, S. Marder, S. Thayumanavan, R. J. Twieg, A. C. Kowalczyk, X. Q. Zhang, and H. S. Lackritz, Opt. Lett. 25, 332 (2000).

${ }^{8}$ A. M. Cox, R. D. Blackburn, D. P. West, T. A. King, F. A. Wade, and D. A. Leigh, Appl. Phys. Lett. 68, 2801 (1996).

${ }^{9}$ C. Poga, D. M. Burland, T. Hanemann, Y. Jia, C. R. Moylan, J. J. Stankus, R. J. Twieg, and W. E. Moerner, Proc. SPIE 2527, 150 (1995).

${ }^{10}$ R. J. Twieg, K. M. Betterton, D. M. Burland, V. Y. Lee, R. D. Miller, C. R. Moylan, W. Volksen, and C. A. Walsh, Proc. SPIE 2025, 94 (1993).

${ }^{11}$ R. J. Twieg, D. M. Burland, J. L. Hedrick, V. Y. Lee, R. D. Miller, C. R. Moylan, W. Volksen, and C. A. Walsh, Mater. Res. Soc. Symp. Proc. 328, 421 (1994).

${ }^{12}$ C. E. Barnes, J. Am. Chem. Soc. 67, 217 (1945).

${ }^{13}$ G. Scott, Atmospheric Oxidation and Antioxidants (Elsevier, Amsterdam, 1965).

${ }^{14}$ N. S. Allen, Polym. Degrad. Stab. 44, 357 (1994). 